\title{
The Salt of the Sea
}

"There are many different salts in the sea."

\author{
"The most convenient, and on the whole the most satisfactory, \\ method of determining salinity is a chemical one..."
}

"As the range in the open oceans is rather small, it is sometimes convenient

to use a salinity of 35 parts per thousand as an average for all oceans." ${ }^{2}$

"All of us have in our veins the exact same percentage of salt in our blood, that exists in the ocean, and, therefore, we have salt in our blood, in our sweat, in our tears. We are tied to the ocean." ${ }^{3}$

THERE IS PROBABLY nothing more foundational to understanding the ocean than the study of salinity. New discoveries regarding its magnitude and variability continue to feed our knowledge of the nature of the marine environment. From the earliest seagoing civilizations, which learned that the buoyancy of their ships might vary in waters of different salt content, to the modern navies of the world, who strive to tune acoustic systems to perform optimally within densitydependent sound velocity profiles, we have wondered at the nature of ocean salinity.

This issue of Oceanography, focusing on salinity, demonstrates that even as our science of oceanography grows, we continue to revisit our roots. In many regards, we view our community in the same light; we continue to expand and diversify the disciplinary portfolio of oceanography, but we rely heavily on the foundation of ocean research. How fitting it is, then, that this issue of Oceanography coincides with the 2008 Ocean Sciences meeting, where we will celebrate the twentieth anniversary of the Society, and where over 3000 abstracts will reflect on the growth of our science. Just for kicks, look at how many of these thousands of papers, presentations, and posters depend on a data foundation that includes salinity information; I suspect you will find that holds true for the vast majority of our science.

Equally exciting is the dramatic expansion of the technological aspects of salinity measurement. Many TOS members will remember (although I doubt they will do so fondly) the backbreaking and extraordinarily labor-intensive efforts of drawing discrete water samples from bottles on a wire, and running them-one by one-through the shipboard salinometer-a monstrous contraption that required rigorous and frequent recalibration-only to repeat the process as the next station on the survey line was reached. Now, look through these pages and understand the extraordinary progress we've made in real-time observations and remote sensing of salinity, not to mention the diversity of applications we've developed.

So, sit back, enjoy this special issue, and think about the progress our community will continue to make in salinity observations, something we can surely celebrate at the TOS twentieth anniversary! I know we'll do so-after all, the TOS membership really is the salt of the earth.

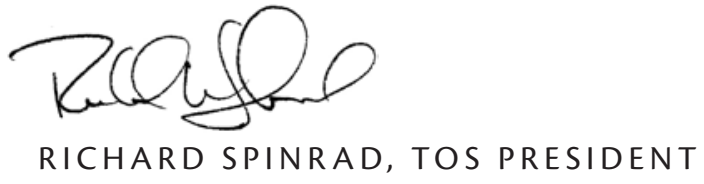

\footnotetext{
1 The Depths of the Ocean, J. Murray and J. Hjort, MacMillan \& Co., 1912

${ }^{2}$ The Oceans, H.U. Sverdrup, M.W. Johnson and R.H. Fleming, Prentice-Hall, 1942

${ }^{3}$ John F. Kennedy, Speech given at Newport at the dinner before the America's Cup Races, September 1962
} 